\title{
Comparison of Calcaneal Eversion, Gastrocnemius Extensibility and Angle of Toe-Out between Normal and Overweight Females
}

\author{
by Megha Masaun ${ }^{1 \otimes}$, P. Dhakshinamoorthy ${ }^{2 \otimes}$, Rahul Singh Parihar $^{3 凶}$
}

The Foot and Ankle Online Journal 2 (8): 2

Background: Obesity is a major health problem worldwide. An increase in body weight is considered to cause overload of the foot, which represents the interface between the body and ground. This can induce various stress and strains during walking that can predispose to overuse injuries of the lower limb.

Purpose: To compare and correlate the effect of weight on calcaneal eversion, gastrocnemius extensibility and angle of toe-out.

Method: Forty females with a mean age of 24.3 years were divided into 2 groups according to their body mass index $(B M I)$. Group $A(n=20, B M I=19-24)$ and Group $B(n=20, B M I=25-29)$. Measurements for calcaneal eversion were obtained in double limb and single limb stance, whilst gastrocnemius extensibility was obtained in a prone position. The angle of toe-out was obtained during walking.

Result: There was a significant difference $(p<0.05)$ between the two groups for double limb stance, gastrocnemius extensibility and angle of toe-out. No significant difference $(p>0.05)$ was noted for single limb stance.

Conclusion: The angle of calcaneal eversion and angle of toe-out are greater in overweight individuals, whilst gastrocnemius extensibility is greater in normal subjects.

Key words: Calcaneal eversion, gastrocnemius extensibility, angle of toe-out, weight, body mass index (BMI) reproduction in any medium, provided the original work is properly cited. (The Foot and Ankle Online Journal (www.faoj.org)

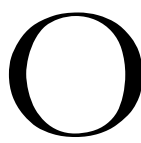
besity is a major worldwide health problem where the body weight is more than $20 \%$ of the ideal. There are many long-term debilitating effects of obesity that may impair quality of life. These include cardiovascular disease, diabetes mellitus and various musculoskeletal disorders.

\footnotetext{
Address correspondence to: Megha Masaun, email: meghamasaun115@yahoo.com

Qualification- MPTh (Neurology), Institution and Address- Department of Physiotherapy, SBSPGI, Balawala, Dehradun, Uttarakhand-248161, India 2 Senior Lecturer, Qualification- MPTh (Sports Medicine).

Institution and Address- Department of Physiotherapy, SBSPGI, Balawala, Dehradun , Uttarakhand-248161, India.

3 Lecturer, Qualification- MPT (Sports)Institution and Address- Department of Physiotherapy, SBSPGI, Balawala, Dehradun , Uttarakhand-248161, India.
}

Of these musculoskeletal disorders, foot problems in obese adults are most important. This may be due to the increased stress placed on the feet through the need to bear excessive mass. ${ }^{1}$

Foot problems are frequent because the interface between body and ground is subjected to high stresses and load. ${ }^{2}$ The foot provides a stable support for the body, attenuates impact and rotational forces, provides sensory information ${ }^{3}$, and combines flexibility and stability for propulsion of body. ${ }^{4,5}$

The rearfoot acts as the central mechanism and a major weight bearing structure during stance. ${ }^{6}$ However, excessive pronation has been linked with injuries due muscle imbalance which disrupt normal lower limb alignment. 
This malalignment is thought to place undue stress and strain on the joints, ligaments and muscles. ${ }^{7}$

One of the common muscle imbalances that affect the ankle joint is a tight gastrocnemius-soleus ${ }^{5}$ These muscles use $85 \%$ of their voluntary contraction during normal walking to help restrain the body's forward momentum by working eccentrically and concentrically. ${ }^{8}$

\section{Purpose of the Study}

To compare the effect of weight on calcaneal eversion, gastrocnemius extensibility and angle of toeout. A further aim was to establish the correlation between calcaneal eversion, gastrocnemius extensibility and angle of toe-out.

\section{Hypothesis}

There will be an effect of weight on calcaneal eversion, gastrocnemius extensibility and angle of toeout.

\section{Methodology}

Subjects: Female students of SBSPGI, Balawala, Dehradun took part in the study. All data were collected at the Research Laboratory, Department of Physiotherapy, SBSPGI, Dehradun. Forty female subjects with a mean age of $21.1 \pm 1.0$ years were divided into 2 groups based on their Body Mass Index (BMI). Twenty females with a mean age of $21.8 \pm 1.8$ years with $\mathrm{BMI}=19-24$ were assigned to Group A (normal). A further twenty females with a mean age of $20.5 \pm 1.6$ with $\mathrm{BMI}=25-29$ were assigned to Group B (overweight).

Table 1 shows the subjects information. None of the subjects had a history of congenital deformity, ligament injury, other soft tissue injury, fracture, pain, limb length discrepancy at least 6 months prior to the start of the study. Informed consent was obtained from all the subjects prior to participation.
Protocol

Group A $(n=20):$ BMI $=19-24$ (normal)

Group B $(n=20)$ : BMI $=25-29$ (overweight)

1. Measurement of calcaneal eversion in double and single limb stance.

2. Measurement of gastrocnemius extensibility in prone position

3. Measurement of angle of toe-out during walking

\section{Procedure}

Subject's height and weight was determined for calculating BMI as per Quetel's Index: $*^{9,10}$

$$
\begin{array}{r}
\text { BMI = Weight } \overline{(\mathrm{Kg})} \\
\text { Height }\left(\mathrm{M}^{2}\right)
\end{array}
$$

*Measurements were taken for double limb stance (DLS), single limb stance (SLS), angle of turn out (ATO) and gastrocnemius extensibility (GE). Two measurements were taken and the average was calculated.

\section{Measurement of Calcaneal Eversion}

Subtalar joint eversion was determined with subjects positioned prone with lower half of calf off the edge of plinth. Sliding calipers were used to identify mid points on the calf and calcaneus and lines were drawn along the midlines on the posterior third of calf and calcaneus. Range of eversion was measured using a goniometer. The axis of standard goniometer was placed between the malleoli in the frontal plane. The stationery arm of goniometer was placed over the line on the posterior region of the calf and the movable arm was placed over the line on posterior calf. 


\begin{tabular}{|c|c|c|c|c|}
\hline GROUP & $\begin{array}{c}\text { AGE } \\
\text { MEAN } \pm \text { SD } \\
\text { (years) }\end{array}$ & $\begin{array}{c}\text { HEIGHT } \\
\text { MEAN } \pm \text { SD } \\
\text { (meters) }\end{array}$ & $\begin{array}{l}\text { WEIGHT } \\
\text { MEAN } \pm \text { SD } \\
\text { (kilograms) }\end{array}$ & $\begin{array}{c}\text { BMI } \\
\text { MEAN } \pm \text { SD }\end{array}$ \\
\hline Group A & $21.8 \pm 1.90$ & $1.56 \pm 0.07$ & $53.37 \pm 4.44$ & $21.50 \pm 1.62$ \\
\hline Group B & $20.55 \pm 1.63$ & $1.57 \pm 0.07$ & $63.65 \pm 5.89$ & $26.64 \pm 1.72$ \\
\hline P Value & $S$ & NS & S & S \\
\hline
\end{tabular}

Table 1 Description of of subjects. $S=$ Significant $(p<0.05)$; NS = Not Significant $(p>0.05)$; SD = standard deviation.

The calcaneus was passively everted to obtain subtalar joint range of motion (ROM). This method of approach has shown good intrarater reliability with Elveru, et al., reporting intraclass correlation coefficients of 0.75 for calcaneal eversion. ${ }^{11}$ This measurement was repeated in double limb stance and single limb stance. ${ }^{2}$

\section{Measurement of Gastrocnemius Extensibility}

The subject was positioned in prone position and a marker was used for marking the fibular head, lateral malleolus, base of $5^{\text {th }}$ metatarsal tuberosity and $5^{\text {th }}$ metatarsal head. The stationary arm of the goniometer was placed along the long axis of fibula by using the mark on the fibular head and the lateral malleolus. The moving arm of the goniometer was then placed parallel to the lateral border of the foot by using the marks on the base and head of $5^{\text {th }}$ metatarsal. The axis of the goniometer was kept on the lateral border of the foot. The zero position of dorsiflexion was defined as $90^{\circ}$ between the long axis of fibula and the lateral border of the foot. All measurements were recorded as the subjects achieved maximum dorsiflexion. ${ }^{12,13}$

\section{Measurement of Angle of Toe-Out}

A 3-meter walkway was created using crepe paper. A chair was placed at the end of walkway to provide orientation during the ambulation trail. Water-soluble ink was applied to the plantar surface of the right foot.
The subject was instructed to walk along the walkway. If they hesitated or no imprint was obtained, the trail was repeated. From the second footprint, three consecutive footprints were evaluated for angle of toe-out. The line parallel to the edge of paper represented the line of progression. The longitudinal axis of footprint was determined as the line drawn from bisecting the widest part of heel through the center of $2^{\text {nd }}$ toe. The angle between line of progression and longitudinal foot axis presented the angle of toe-out. The average of all 3 right foot prints was calculated. $^{14}$

\section{Data Analysis}

The significance level selected was 0.05. An independent $t$-test was performed for comparing calcaneal eversion, gastrocnemius extensibility and angle of toe-out between Group A (normal) and Group B (overweight). A Pearson's correlation coefficient was calculated to establish the association between the variables within Group A and B.

\section{Results}

Subjects Information: Independent t-test was performed for comparing age, height, weight and BMI in Group A and B which showed significant value. $(p<0.05)$ (Table 1$)$ 


\begin{tabular}{|c|c|c|c|c|}
\hline GROUP & $\begin{array}{c}\text { DLS (V1) } \\
\text { MEAN } \pm \mathrm{SD}^{\circ}\end{array}$ & $\begin{array}{c}\text { SLS (V2) } \\
\text { MEAN }^{\circ} \pm \mathrm{SD}^{\circ}\end{array}$ & $\begin{array}{c}\text { GE (V3) } \\
\text { MEAN }^{\circ} \pm \mathrm{SD}^{\circ}\end{array}$ & $\begin{array}{c}\text { ATO (V4) } \\
\text { MEAN }^{\circ} \pm \mathrm{SD}^{\circ}\end{array}$ \\
\hline Group A & $8.6 \pm 1.0$ & $11.1 \pm 1.1$ & $11.6 \pm 2.7$ & $9.4 \pm 2.8$ \\
\hline Group B & $10.2 \pm 1.5$ & $11.8 \pm 3.0$ & $9.5 \pm 2.5$ & $11.6 \pm 1.9$ \\
\hline P Value & $\mathrm{S}$ & NS & $\mathrm{S}$ & $\mathrm{S}$ \\
\hline
\end{tabular}

Table 2 Description of subjects. $S=$ Significant $(p<0.05)$; NS = Not Significant $(p>0.05)$; SD = standard deviation. (DLS: Double Limb Stance, SLS: Single Limb Stance; GE: Gastrocnemius Extensibility; ATO: Angle of Toe-Out)

\begin{tabular}{|c|c|c|}
\hline VARI ABLES & GROUP A ( $\boldsymbol{r}$ VALUE ) & GROUP B ( $\boldsymbol{r V A L U E )}$ \\
\hline DLS versus SLS & 0.65 & 0.47 \\
\hline DLS versus v/s GE & 0.22 & 0.02 \\
\hline SLS versus GE & 0.44 & -0.05 \\
\hline SLS versus ATO & -0.26 & -0.004 \\
\hline GE versus ATO & 0.11 & -0.26 \\
\hline
\end{tabular}

Table 3 Correlation between variables of Groups A and B. (DLS: Double Limb Stance, SLS: Single Limb Stance; GE: Gastrocnemius Extensibility; ATO: Angle of Toe-Out)

\section{Comparison of variables between Group $A$ and B:}

Independent t-test results showed Significant $(\mathrm{P}<$ 0.05) values for DLS, GE and ATO with mean for DLS in Group A and B $\left(8.6^{\circ} \pm 1.0^{\circ}\right.$ and $10.2^{\circ} \pm 1.5^{\circ}$ respectively). The mean value of GE in Group $A$ and $\mathrm{B}$ is $11.6^{\circ} \pm 2.7^{\circ}$ and $9.5^{\circ} \pm 2.5^{\circ}$ respectively. The mean value for ATO between Group A and B is $9.4^{\circ}$ $\pm 2.8^{\circ}$ and $11.6^{\circ} \pm 1.9^{\circ}$ respectively. The result showed no significant $(\mathrm{p}>0.05)$ differences for SLS with the mean for Group $A$ and B at $11.1^{\circ} \pm 1.1^{\circ}$ and the mean for Group $A$ and $B$ at $11.1^{\circ} \pm 1.1^{\circ}$ and $11.8^{\circ} \pm 3.0^{\circ}$ respectively (graph 1 , table 2 )

(C) The Foot and Ankle Online Journal, 2009

\section{Correlation between variables:}

For Group A (Normal): The DLS and SLS showed a positive correlation $(r=0.65)$. DLS and GE have a weak positive correlation $(r=0.22)$. SLS and GE share a positive correlation $(r=0.44)$. SLS and ATO have a weak positive correlation $(r=0.11)$ Table 3 shows the correlation between the variables in Group $\mathrm{A}$ and $\mathrm{B}$. 


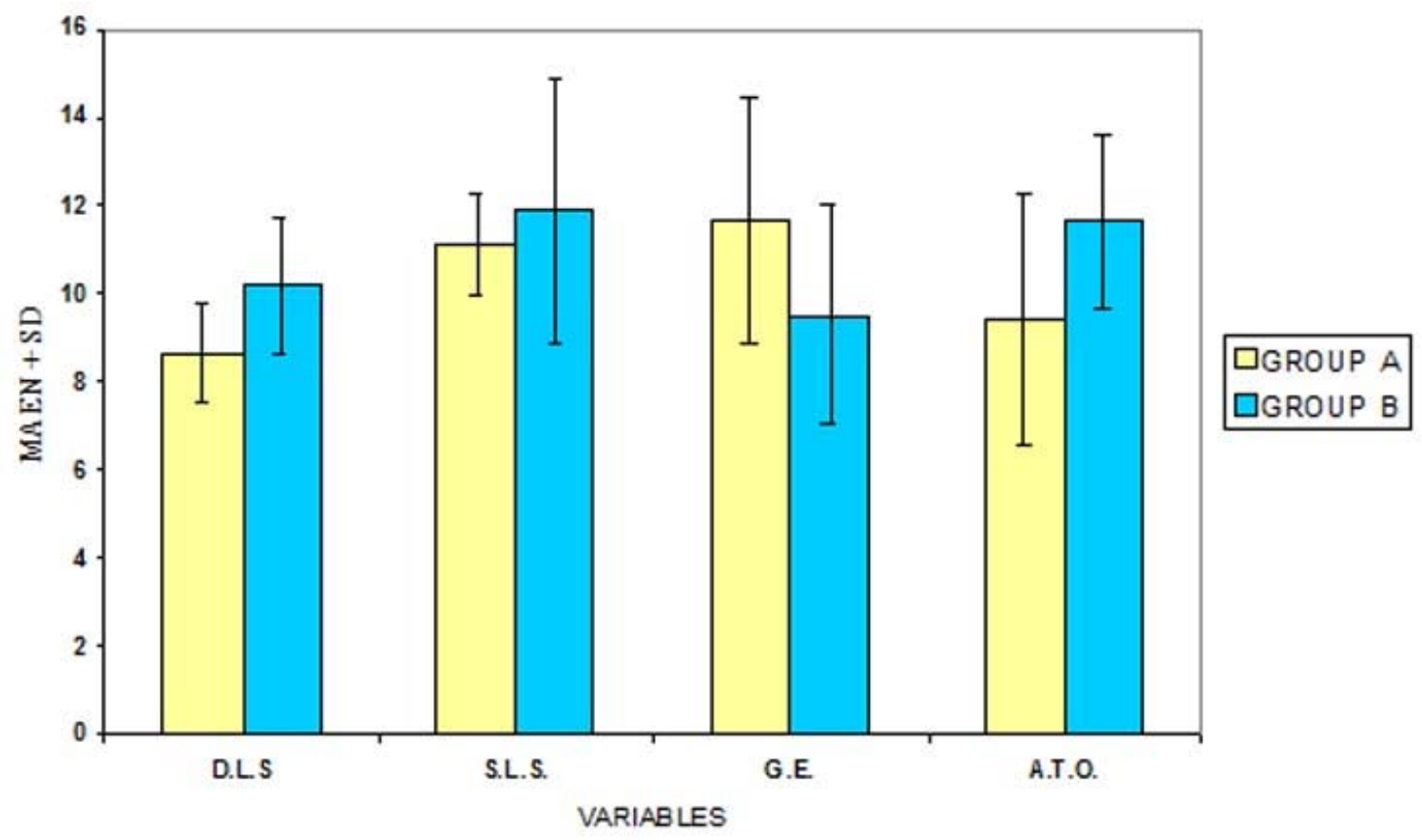

Graph 1 Comparison of variables between Group A and B. (mean values presented in degrees; DLS: Double Limb Stance, SLS: Single Limb Stance; GE: Gastrocnemius Extensibility; ATO: Angle of Toe-Out)

For Group B (overweight): The DLS and SLS have a positive correlation $(r=0.47)$. DLS and GE have a very weak positive correlation $(r=0.02)$. SLS and GE have weak negative correlation $(r=-0.05)$. SLS and ATO have very weak negative correlation $(r=-.004)$. While GE and ATO have negative correlation $(r=-0$ .26)

\section{Discussion}

The significant difference for the double limb stance for Group A and Group B can be due to the extra load through arches of the foot. Schiew and Andrew (2000) suggested a link between higher body mass and flattening of the arches. ${ }^{15}$ Moreover, Hall and Broody (1999) also concluded that obesity has an excessive pronatory effect. ${ }^{16}$ The results showed no significant difference between the two Groups in SLS. These findings are in contrast to Steven, et al., (2004) who suggested that obesity can contribute to excessive pronation and foot pain. ${ }^{7}$
According to the results, GE is less in the overweight, this could be due to the subjects presenting with excessive pronation, which causes shortening of the tendo-Achilles (Harris and Beath,1948) and instability at the subtalar and midtarsal joints. ${ }^{17}$ Overweight subjects showed greater ATO which is supported by Charette (2002) as they have an increased foot flare during walking. ${ }^{18}$ Kendall (1993) concluded that in the weight bearing position, there is flatness of longitudinal arch, which is usually accompanied by out-toeing. ${ }^{19}$

There is a positive correlation between SLS, calcaneal eversion and GE in normal subjects, but a negative correlation in overweight subjects. This may be because there is a greater calcaneal eversion in subjects who are overweight, which can lead to less active ROM of ankle dorsiflexion. According to Charrete (2002), excessive pronation is due to tight a tight tendo-Achilles (as stated above) or gastro-soleal equinus. ${ }^{18}$ Coetzee (2004) also concluded that the tight Achilles can cause eversion of the calcaneus. ${ }^{7}$ 
The compensation for reduced ankle dorsiflexion takes place at the subtalar and midtarsal joints in the form of excessive pronation. ${ }^{20}$ The results reported showed a weak positive correlation between GE and the angle of toe-out in normal subjects and a negative correlation in the overweight subjects. Magee (2002) concluded that toe-out may present due to contracture of the gastrocnemius and soleus. ${ }^{8}$

There is a very weak negative correlation between SLS, calcaneal eversion and AOT. The same result has also been proved by Kernozek (1990), but is contrary to Lapidus who stated that individuals with abducted foot tend to pronate more. ${ }^{21}$ Chang, et al.,(2004) concluded that increased out-toeing increases pressure on the medial foot and provides mechanical force directed at the valgus foot. The intoeing gait unloads the medial foot and increases the severity of the varus foot. ${ }^{22}$

The hypothesis proves that increased weight has an effect on calcaneal eversion, angle of toe-out and gastrocnemius extensibility. This is because extra weight puts stress on the foot causing flattening of the arches Kapandji (1985). Severely obese females have significantly greater rearfoot motion and foot angle values than normal weight females ${ }^{23}$ which can lead to certain dysmorphism of foot specially flat foot. $^{15}$

The differences found between weight bearing and non-weight bearing could be the result of gravitational and ground reaction forces imparted to foot which causes excessive pronation leading to Tendo Achilles shortening. Kendall (1993) concluded that in a weight bearing position, there is flatness of longitudinal arch that is usually accompanied by out toeing (i.e. increased ATO). ${ }^{19}$ An out toe position was found in subjects with a tight gastrocnemius. This result is found in overweight because toeing out in walking may result from tightness of tendo Achilles. ${ }^{19}$ This is likely to place strain on structures associated with the longitudinal arch as weight is transferred from heels to toes. ${ }^{13}$

\section{Conclusion}

Calcaneal Eversion and Angle of Toe Out are more in Overweight whereas Gastrocnemius Extensibility is less in Overweight when compared with Normal subjects. A positive correlation has been found between Double Limb Stance and Single Limb Stance, Double Limb Stance and Gastrocnemius Extensibility, Single Limb Stance and Gastrocnemius Extensibility, Gastrocnemius Extensibility and Angle of Toe Out and a negative correlation between Single Limb Stance and Angle of Toe-Out in Group A.

There is a positive correlation between Double Limb Stance and Single Limb Stance, Double Limb Stance and Gastrocnemius Extensibility and a negative correlation between Single Limb Stance and Gastrocnemius Extensibility, Gastrocnemius Extensibility and Angle of Toe-Out, Single Limb Stance and Angle of Toe-Out in Group B.

\section{Acknowledgement}

We are thankful to all the staff members of SBSPGI, Balawala, Dehradun. 


\section{References}

1. Riddiford-Harland DL, Steele JR, Storlien LH: Does obesity influence foot structure in prepubescent children? International J Obesity 24 (5): 541 - 544, 2000.

2. Valmassy RL: Clinical Biomechanics of Lower Extremities. St. Louis, MO: Mosby, 1996.

3. Hennig EM: The Human Foot During Locomotion- Applied Research for Footwear, 2002.

http://www.cuhk.edu.hk/iso/weilun/en/hennig/hennig fulltex t1.html Accessed 27th July 2009.

4. Vicenzino B, Fielding J, Howard, R, Moore R, Smith S: An Investigation of the antipronation effect of two taping methods after application and exercise. Gait Posture 5: 1 - 5, 1997.

5. Doxey GE: Calcaneal pain - A review of various disorders. J Bone Joint Surg 72A $884-888,1987$.

6. Karas A, Hoy J: Compensatory midfoot dorsiflexion in individuals with heelcord tightness. J Prosthetics Orthotics 14 (2) $82-93,2002$.

7. Stovitz SD, Coetzee JC. Hyperpronation and foot pain: step toward painfree feet. Physician Sports Medicine 32 (8): 1 - 10, 2004.

8. Magee DJ: Orthopaedic Physical Assessment. $4^{\text {th }}$ edition, WB Saunders, Philadelphia, 2002.

9. Garrett WG, Kirkendall DT: Exercise and Sports Science. Lippincott Williams and Wilkins, Philadelphia, 2000.

10. Pryor J, Prasad A, Ammani S: Physiotherapy for Respiratory and Cardiac Problems. $3^{\text {rd }}$ edition, Churchill Livingstone, Edinburgh, 2001.

11. Johanson MA, Donatelli R, Wooden MJ, Andrew P, Cumminge GS: Effects of three different posting methods on controlling abnormal subtalar pronation. Physical Therapy 79 (2): $149-158,1994$.

12. Wang SS, Whitney SL, Burdett RG, Janosky JE: Lower extremity muscular flexibility in long distance runners. 17 (2): $102-107,1993$.

13. Wessling KC, Devane DA, Hylton CR: Effects of static stretch versus static stretch and US combined on triceps surae muscle extensibility in healthy women. Physical Therapy 6 (5): 674-679, 1987.

14. Rossner Buchanan K, Davis IM. The relationship between forefoot, midfoot and rearfoot static alignment in pain-free individuals. J Orthopaedic Sports Physical Therapy 35 (9) 559 $566,2005$.

15. van Schie CHM, Boulton AJM: The effect of arch height and body mass on plantar pressure wounds 12(4): 88 - 95, 2000.

16. Hall CM, Thein Broody L: Therapentic Exercises - Moving Towards Function. Lippincott and Wilkins, Philadelphia, 1999.

17. Harris RI, Beath T: Hypermobile flatfoot with short Tendo Achilles. J Bone Joint Surg 30A 116 - 150, 1948.

18. Charrette M: Orthotic Support for Overweight and Obese patients- The Chiropractic Journal, 2002. http://www.worldchiropracticalliance.org/tcj/2002/jul/jul2002

charrette.htm Accessed 27th July, 2009.
19. Kendall FP, McCreary EK, Provance PG: Muscles: Testing and Function. 4th edition. Williams and Wilkins; Baltimore, 1993.

20. Brown LP, Yavorsky P: Locomotor biomechanics and pathomechanics: A review. J Orthopaedic Sports Physical Therapy 9 (1) 3-10, 1987.

21. Kernozek TW, Ricard MD: Foot placement angle and arch type: Effect on rearfoot angle. Arch Phys Med Rehabilitation 71 (12) 988 - 991, 1990.

22. Chang WN, Tsirikos AI, Miller F, Schuyler J, Glutting J: Impact of changing FPA on foot pressure measurement in children with neuromuscular diseases. Gait Posture 20 (1): 14 19, 2004.

23. Messier SP, Davies AB, Moore DT, Davis SE, Pack RJ, Kazmar SC: Severe obesity: Effects on foot mechanics during walking. Foot Ankle Int 15(1);29-34, 1994. 